\title{
PENGARUH PRODUK, HARGA, KUALITAS PELAYANAN, PROMOSI DAN LOKASI TERHADAP KEPUTUSAN KONSUMEN BERKUNJUNG DI KAMPOENG BANYUMILI SEMARANG JAWA TENGAH
}

\author{
THE INFLUENCE OF PRODUCT, PRICE, SERVICE QUALITY, PROMOTION AND \\ LOCATION ON CUNSUMER DECISIONS TO VISITING THE KAMPOENG \\ BANYUMILI SEMARANG CENTRAL JAVA
}

\author{
DEVITA CHIRSTY PUTRI*, LASMONO TRI SUNARYANTO \\ Fakultas Pertanian dan Bisnis Universitas Kristen Satya Wacana \\ Jalan Diponegoro 52-60, Salatiga, Jawa Tengah \\ *E-mail: 522016046@ student.uksw.edu
}

\begin{abstract}
ABSTRAK
Keputusan konsumen merupakan tahap dalam proses keputusan pembelian, dimana konsumen benarbenar membeli suatu barang atau jasa. Proses keputusan pembelian konsumen meliputi tahap pengenalan kebutuhan, pencarian informasi, evaluasi alternatif, pembelian dan evaluasi pasca pembelian. Kampoeng Banyumili merupakan agrowisata (restoran, pemancingan dan outbound) yang memiliki panorama alam yang indah yang sedang ramai dikunjungi pengunjung. Tingginya kegiatan pembelian dilihat dari jumlah konsumen yang datang dan melakukan pembelian. Tujuan dari penelitian ini adalah untuk mengetahui pengaruh produk, harga, kualitas pelayanan, promosi dan lokasi terhadap keputusan konsumen berkunjung di Kampoeng Banyumili. Penelitian dilaksanakan pada bulan Januari hingga Februari 2020. Teknik analisis yang digunakan adalah analisis regresi linear berganda. Teknik pengambilan sampel yang digunakan adalah insidental sampling dengan jumlah sampel sebanyak 30 sampel. Hasil penelitian menunjukan bahwa variabel harga $\left(\mathrm{X}_{2}\right)$, variabel kualitas pelayanan $\left(\mathrm{X}_{3}\right)$ dan variabel promosi $\left(\mathrm{X}_{4}\right)$ berpengaruh positif dan signifkan terhadap keputusan konsumen berkunjung. Sedangkan variabel produk $\left(\mathrm{X}_{1}\right)$ dan variabel lokasi $\left(\mathrm{X}_{5}\right)$ tidak berpengaruh signifikan terhadap keputusan konsumen berkunjung di Kampoeng Banyumili.
\end{abstract}

Kata Kunci: Harga, Kualitas Pelayanan, Promosi, Keputusan Konsumen, Kampoeng Banyumili

\begin{abstract}
Cumsumer decisions are part of the purchasing decision process, where the consumers literally buy an item or service. Consumer purchasing decision process needs, information search, alternative evaluation, purchase and post-purchase evaluation. Kampoeng Banyumili is an agro-tourism (restaurant, fishing ground and outbound) place that has a beautiful natural panorama that is being visited by visitors. The high purchase program can be seen from the amount consumers who come and make a purchase. The purpose of this research is to study the effect of the product, price, service quality, promotion and location on cumsumer visiting decisions in Kampoeng Banyumili. The study was conducted in January to February 2020. The analysis technique used is multiple linear regression analysis. The sampling technique is using incidental technique with a total sample of 30 samples. Research result shows that the price variable $\left(X_{2}\right)$, service quality variable $\left(X_{3}\right)$ and pormotion variable $\left(X_{4}\right)$ react positively and significantly to consumers visiting decisions. While the product variables $\left(X_{1}\right)$ and location variables $\left(X_{5}\right)$ are not significant to the consumers visiting decisions at Kampoeng Banyumili.
\end{abstract}

Keywords: Price, Service Quality, Promotion, Consumers Visiting Decisions, Kampoeng Banyumili 


\section{PENDAHULUAN}

Manusia adalah makhluk sosial yang memiliki sifat yang berbeda, namun memiliki kebutuhan dasar yang sama dalam hidupnya. Teori hierarki kebutuhan menurut Maslow dalam Setiadi (2010), menyatakan bahwa setiap manusia memiliki kebutuhan dasar yang bertingkat mulai dari yang terendah hingga tertinggi yaitu kebutuhan fisiologi, kebutuhan rasa aman, kebutuhan sosial, kebutuhan harga diri dan kebutuhan aktualitas diri. Dalam memenuhi kebutuhannya, setiap manusia akan berusaha untuk memenuhi kebutuhan paling dasar terdahulu sebelum timbul keinginan untuk merasakan kebutuhan yang lebih tinggi. Kebutuhan tingkat pertama yang harus terpenuhi adalah kebutuhan fisiologis. Salah satu kebutuhan fisiologis adalah kebutuhan akan pangan atau makanan yang merupakan salah satu kebutuhan dasar atau kebutuhan pokok manusia yang harus terpenuhi sebagai sumber nutrisi dan energi untuk keberlangsungan hidupnya.

Seiring berjalannya waktu, perkembangan penduduk di suatu wilayah akan semakin bertambah dan secara tidak langsung kebutuhan pangan cenderung akan terus meningkat. Semakin bertambah penduduk di wilayah tersebut, maka akan semakin tinggi pula tingkat konsumsi masyarakat. Tingginya tingkat konsumsi dimasyarakat dapat menyebabkan terjadinya persaingan antar bisnis restoran. Hal ini ditandai dengan banyaknya restoran yang mulai muncul dan berkembang di berbagai daerah dengan keunggulannya masing-masing.

Melihat tingginya permintaan pasar akan makanan dan disertai dengan daya beli masyarakat yang tinggi, bisnis restoran merupakan salah satu bisnis yang sangat potensial dan menjanjikan. Mengkonsumsi makanan di restoran tidak hanya dilakukan untuk menghilangkan rasa lapar, tetapi juga dapat dijadikan sebagai tempat berkumpul dan sekadar untuk menenangkan pikiran. Perubahan gaya hidup dapat disebabkan dari pergaulan atau lingkungan sekitar, aktivitas keseharian serta perkembangan zaman (Puspita, 2014). Dengan kesibukan yang ada, cenderung memicu masyarakat menginginkan suatu makanan yang mudah diperoleh, praktis, dan membutuhkan tempat yang nyaman untuk dapat menyegarkan pikiran.

Kampoeng Banyumili merupakan sebuah tempat wisata yang berada dibawah naungan PT. Banyumili Agro Lestari yang bergerak di bidang Agrowisata (restoran, pemancingan, dan outbond) memiliki panorama alam yang indah berupa 
hamparan sawah yang luas, pebukitan dan pegunungan. Dengan lokasi yang strategis ini, mampu meningkatkan kegiatan pembelian di Kampoeng Banyumili. Tingginya kegiatan pembelian dapat dilihat dari jumlah konsumen yang datang berkunjung dan melakukan pembelian di Kampoeng Banyumili tersebut.

Kegiatan pembelian merupakan salah satu tahap dari keseluruhan proses keputusan pembelian konsumen. Proses keputusan pembelian konsumen meliputi tahap pengenalan kebutuhan, pencarian informasi, evaluasi alternatif, pembelian, dan evaluasi proses pembelian Dalam menentukan pilihannya, konsumen tentunya mempunyai pertimbangan tertentu dan terdapat hal-hal yang paling berpengaruh diantaranya adalah faktorfaktor seperti produk yang disajikan, harga, kualitas pelayanan, promosi dan lokasi yang dilakukan tempat usaha untuk dapat menarik minat konsumen (Kotler, 2001).

Sejalan dengan pemahaman diatas, maka peneliti tertarik melakukan penelitian dengan tujuan mengetahui pengaruh produk, harga, kualitas pelayanan, promosi dan lokasi terhadap keputusan berkunjung di Kampoeng Banyumili Semarang Jawa Tengah.

\section{METODE PENELITIAN}

Penelitian dilakukan di Kampoeng Banyumili, Kabupaten Semarang, Jawa Tengah pada bulan Januari hingga Februari 2020. Pemilihan lokasi penelitian dilakukan secara sengaja (purposive) dengan alasan bahwa Kampoeng Banyumili bergerak pada sektor agrowisata (retoran, outbound dan pemancingan) yang sedang ramai dikunjungi masyarakat. Metode penelitian yang digunakan adalah metode survei. Teknik pengambilan sampel yang digunakan adalah teknik insidental sampling dengan pendekatan non-probabiliy sampling. Oleh karena jumlah populasi sampel tidak diketahui, maka jumlah sampel penelitian diambil sebanyak 30 sampel (responden). Hal ini sesuai dengan pernyataan Roscoe dalam Sugiyono (2009), bahwa ukuran sampel yang layak dalam penelitian adalah minimal antara 30 sampai dengan 500 sampel. Variabel penelitian yang digunakan adalah variabel independen dan variabel dependen. Variabel independen pada penelitian ini adalah variabel produk $\left(\mathrm{X}_{1}\right)$, harga $\left(\mathrm{X}_{2}\right)$, kualitas pelayanan $\left(\mathrm{X}_{3}\right)$, promosi $\left(\mathrm{X}_{4}\right)$, lokasi $\left(\mathrm{X}_{5}\right)$. Variabel dependen penelitian adalah keputusan konsumen berkunjung (Y).

Analisis regresi linear berganda digunakan untuk mengetahui pengaruh 
produk, harga, kualitas pelayanan, promosi dan lokasi terhadap keputusan konsumen berkunjung di Kampoeng Banyumili sebagai berikut:

$Y=a+b_{1} X_{1}+b_{2} X_{2}+b_{3} X_{3}+b_{4} X_{4}+b_{5} X_{5}+e$

Keterangan:

$\mathrm{Y}=$ keputusan konsumen berkunjung

$\mathrm{X}_{1}=$ produk

$\mathrm{X}_{2}=$ harga

$\mathrm{X}_{3}=$ kualitas pelayanan

$\mathrm{X}_{4}=$ promosi

$\mathrm{X}_{5}=$ lokasi

$\mathrm{a}=$ konstanta

$\mathrm{b}=$ koefisien regresi $\mathrm{X}_{1}$ sampai dengan $\mathrm{X}_{5}$

$\mathrm{e}=$ tingkat kesalahan (error)

\section{HASIL DAN PEMBAHASAN}

\section{Instrumen Penelitian}

\section{Uji Validitas}

Uji validitas digunakan untuk mengukur sejauh mana alat ukur dapat mengukur sesuatu yang ingin diukur (Umar, 2005). Hasil uji validitas instrumen penelitian sebagai berikut:

\section{Tabel 1 Uji Validitas}

\begin{tabular}{ccccc}
\hline Variabel & Item & rhitung & rtabel & $\begin{array}{c}\text { Keteran } \\
\text { gan }\end{array}$ \\
\hline Produk & X1.1 & 0,777 & 0,3610 & Valid \\
$\left(\mathrm{X}_{1}\right)$ & $\mathrm{X} 1.2$ & 0,584 & 0,3610 & Valid \\
& $\mathrm{X} 1.3$ & 0,633 & 0,3610 & Valid \\
& $\mathrm{X} 1.4$ & 0,834 & 0,3610 & Valid \\
\hline Harga $\left(\mathrm{X}_{2}\right)$ & $\mathrm{X} 2.1$ & 0,853 & 0,3610 & Valid \\
& $\mathrm{X} 2.2$ & 0,725 & 0,3610 & Valid \\
& $\mathrm{X} 2.3$ & 0,705 & 0,3610 & Valid \\
& $\mathrm{X} 2.4$ & 0,573 & 0,3610 & Valid \\
\hline Kualitas & $\mathrm{X} 3.1$ & 0,709 & 0,3610 & Valid \\
Pelayanan & $\mathrm{X} 3.2$ & 0,735 & 0,3610 & Valid \\
$\left(\mathrm{X}_{3}\right)$ & $\mathrm{X} 3.3$ & 0,658 & 0,3610 & Valid \\
& $\mathrm{X} 3.4$ & 0,727 & 0,3610 & Valid \\
\hline Pomosi & $\mathrm{X} 4.1$ & 0,681 & 0,3610 & Valid
\end{tabular}

\begin{tabular}{ccccc}
$\left(\mathrm{X}_{4}\right)$ & $\mathrm{X} 4.2$ & 0,961 & 0,3610 & Valid \\
& X4.3 & 0,451 & 0,3610 & Valid \\
& X4.4 & 0,673 & 0,3610 & Valid \\
\hline Lokasi $\left(\mathrm{X}_{5}\right)$ & $\mathrm{X} 5.1$ & 0,826 & 0,3610 & Valid \\
& X5.2 & 0,710 & 0,3610 & Valid \\
& X5.3 & 0,400 & 0,3610 & Valid \\
& X5.4 & 0,779 & 0,3610 & Valid \\
\hline Keputusan & Y1.1 & 0,744 & 0,3610 & Valid \\
Konsumen & Y1.2 & 0,643 & 0,3610 & Valid \\
$($ Y) & Y1.3 & 0,862 & 0,3610 & Valid \\
& Y1.4 & 0,680 & 0,3610 & Valid \\
& Y1.5 & 0,754 & 0,3610 & Valid
\end{tabular}

Sumber: Data Primer yang diolah, 2020.

Berdasarkan tabel 1 uji validitas, dapat disimpulkan bahwa instrumen penelitian pada variabel produk $\left(\mathrm{X}_{1}\right)$, harga $\left(\mathrm{X}_{2}\right)$, kualitas pelayanan $\left(\mathrm{X}_{3}\right)$, promosi $\left(\mathrm{X}_{4}\right)$, lokasi $\left(\mathrm{X}_{5}\right)$ dan keputusan konsumen (Y) dinyatakan valid karena nilai $r_{\text {hitung }}>$ $r_{\text {tabel }}$. Hasil penelitian ini sesuai dengan pendapat Arikunto (2006), menyatakan bahwa instrumen penelitian dikatakan valid, apabila memiliki nilai pearson correlaion $\mathrm{r}_{\text {hitung }}>\mathrm{r}_{\text {tabel }}$.

\section{Uji Reliabilitas}

Uji reliabilitas digunakan untuk mengukur derajat ketepatan atau keakuratan suatu instrumen penelitian (Umar, 2005). Berikut adalah hasil uji reliabilitas instrumen penelitian:

\section{Tabel 2 Uji Reliabilitas}

\begin{tabular}{lcl}
\hline \multicolumn{1}{c}{ Variabel Penelitian } & $\begin{array}{c}\text { Cronbach } \\
\text { alpha }\end{array}$ & Keterangan \\
\hline Produk $\left(\mathrm{X}_{1}\right)$ & 0,676 & Reliabel \\
Harga $\left(\mathrm{X}_{2}\right)$ & 0,687 & Reliabel \\
Kualitas Pelayanan $\left(\mathrm{X}_{3}\right)$ & 0,664 & Reliabel \\
Promosi $\left(\mathrm{X}_{4}\right)$ & 0,659 & Reliabel \\
Lokasi $\left(\mathrm{X}_{5}\right)$ & 0,641 & Reliabel \\
Keputusan Konsumen & 0,786 & Reliabel \\
$(\mathrm{Y})$ & & \\
\hline
\end{tabular}

Sumber: Data Primer yang diolah, 2020. 
Berdasarkan tabel 2 uji reliabilitas, dapat diketahui bahwa kuesioner penelitian pada variabel produk $\left(\mathrm{X}_{1}\right)$, harga $\left(\mathrm{X}_{2}\right)$, kualitas pelayanan $\left(\mathrm{X}_{3}\right)$, promosi $\left(\mathrm{X}_{4}\right)$, lokasi $\left(\mathrm{X}_{5}\right)$ dan keputusan konsumen $(\mathrm{Y})$ memiliki nilai cronbach alpha > 0,60, dengan demikian instrumen penelitian tersebut dikatakan reliabel. Hasil penelitian ini sesuai dengan pendapat Ghozali (2012), menyatakan bahwa instrumen penelitian dapat dikatakan reliabel apabila nilai Cronbach Alpha $>0,60$.

\section{Uji Asumsi Klasik}

\section{Uji Normalitas}

Uji normalitas bertujuan untuk melihat apakah dalam model regresi variabel terikat dan bebas mempunyai distribusi normal atau tidak normal. Berikut adalah hasil uji normalitas:

\section{Tabel 3 Uji Normalitas One-Sample} Kolmogorov-Smirnov Test

\begin{tabular}{|ll|r|}
\hline & & $\begin{array}{r}\text { Unstandardized } \\
\text { Residual }\end{array}$ \\
\hline $\mathrm{N}$ & Mean & 30 \\
Normal & .0000000 \\
Parameters & Std. Deviation & 1.43782585 \\
Most Extreme & Absolute & .088 \\
Differences & Positive & .088 \\
& Negative & -.059 \\
Kolmogorov-Smirnov Z & .482 \\
Asymp. Sig. (2-tailed) & $\mathbf{. 9 7 4}$ \\
\hline
\end{tabular}

Sumber: Data Primer yang diolah, 2020

Berdasarkan tabel uji normalitas diatas, menunjukkan bahwa produk $\left(\mathrm{X}_{1}\right)$, harga $\left(\mathrm{X}_{2}\right)$, kualitas pelayanan $\left(\mathrm{X}_{3}\right)$, promosi $\left(\mathrm{X}_{4}\right)$, lokasi $\left(\mathrm{X}_{5}\right)$ memiliki nilai Asymp. Sig (2-tailed) sebesar 0,974 > signifikansi 0,05 , dengan demikian data tersebut dapat dinyatakan berdistribusi normal. Hasil penelitian ini sesuai denga pendapat Lufitasi (2014), menyatakan bahwa uji normalitas dalam penelitian ini menggunakan metode uji KolmogrovSimrnov dengan melihat nilai Asymp. Sig (2-tailed) > signifikan $(0,05)$.

\section{Uji Multikolinearitas}

Uji multikolinearitas bertujuan untuk melihat apakah dalam model regresi ditemukan ada tidaknya korelasi antara variabel bebas. Berikut adalah hasil uji multikolinearitas:

\section{Tabel 4 Uji Multikolinearitas}

\begin{tabular}{lcc}
\hline \multicolumn{1}{c}{ Variabel penelitian } & Tolarence & VIF \\
\hline Produk $\left(\mathrm{X}_{1}\right)$ & 0,902 & 1,108 \\
Harga $\left(\mathrm{X}_{2}\right)$ & 0,747 & 1,338 \\
Kualitas Pelayanan $\left(\mathrm{X}_{3}\right)$ & 0,653 & 1,531 \\
Promosi $\left(\mathrm{X}_{4}\right)$ & 0,723 & 1,384 \\
Lokasi $\left(\mathrm{X}_{5}\right)$ & 0,746 & 1,340 \\
\hline
\end{tabular}

Sumber: Data Primer yang diolah, 2020

Berdasarkan tabel 4 uji multikolinearitas, menunjukkan bahwa variabel produk $\left(\mathrm{X}_{1}\right)$, harga $\left(\mathrm{X}_{2}\right)$, kualitas pelayanan $\left(\mathrm{X}_{3}\right)$, promosi $\left(\mathrm{X}_{4}\right)$, lokasi $\left(\mathrm{X}_{5}\right)$ tidak terjadi masalah multikolinearitas karena pada masing-masing variabel memiliki nilai VIF $<10$ dan Tolarence $>$ 0,1 . Penelitian ini sejalan dengan pendapat Ghozali (2012), bahwa uji normalitas dapat dilihat dari nilai Tolerance dan Variance 
Inflation Factor (VIF) dan model regresi dikatakan tidak mengalami multikolineartias apabilai nilai VIF $<10$ dan tolerance $>0,1$.

\section{Uji Heteroskedastisitas}

Uji heteroskedastisitas bertujuan untuk melihat apakah dalam regresi terjadi ketidaksamaan varian residual dari satu pangamatan kepengamatan lainnya.

Tabel 5 Uji Heteroskedastisitas

\begin{tabular}{|c|c|c|c|}
\hline \multirow{2}{*}{ Variabel penelitian } & \multicolumn{2}{|c|}{$\begin{array}{c}\text { Unstandardized } \\
\text { coefficients }\end{array}$} & \multirow{2}{*}{$\begin{array}{l}\text { Signifi } \\
\text { kansi }\end{array}$} \\
\hline & B & $\begin{array}{c}\text { Std. } \\
\text { Error }\end{array}$ & \\
\hline Constant & 2.487 & 2,551 & 0,339 \\
\hline $\operatorname{Produk}\left(\mathrm{X}_{1}\right)$ & $-0,044$ & 0,101 & 0,668 \\
\hline $\operatorname{Harga}\left(\mathrm{X}_{2}\right)$ & $-0,035$ & 0,079 & 0,664 \\
\hline $\begin{array}{l}\text { Kualitas Pelayanan } \\
\left(\mathrm{X}_{3}\right)\end{array}$ & $-0,159$ & 0,119 & 0,194 \\
\hline Promosi $\left(\mathrm{X}_{4}\right)$ & $-0,073$ & 0,077 & 0,351 \\
\hline Lokasi $\left(\mathrm{X}_{5}\right)$ & 0,203 & 0,113 & 0,083 \\
\hline
\end{tabular}

Sumber: Data Primer yang diolah, 2020

Berdasarkan tabel 5 uji hetoroskedastisitas, menunjukkan bahwa variabel produk $\left(\mathrm{X}_{1}\right)$, harga $\left(\mathrm{X}_{2}\right)$, kualitas pelayanan $\left(\mathrm{X}_{3}\right)$, promosi $\left(\mathrm{X}_{4}\right)$, lokasi $\left(\mathrm{X}_{5}\right)$ tidak terjadi masalah heteroskedastisitas karena pada masing-masing variabel memiliki nilai signifikansi $>0,05$. Hal ini sesuai dengan pendapat Priyatno (2013), menyatakan apabila nilai signifikan $>0,05$ maka model regresi tersebut tidak mengalami gangguan heteroskedastisitas.

\section{Analisi Regresi Linear Berganda}

Berdasarkan hasil analisis data, persamaan regresi linear berganda terkait pengaruh produk, harga, kualitas pelayanan, promosi dan lokasi terhadap keputusan konsumen berkunjung di Kampoeng Banyumili dapat dirumuskan sebagai berikut:

$Y=6.626-0,151 X_{1}+0,367 X_{2}+0,510$

$X_{3}+0,328 X_{4}-0,145 X_{5}$

Dari persamaan regresi linear berganda diatas, dapat dijelaskan sebagai berikut:

1. Nilai $\beta_{0}=$ konstanta 6,626 artinya jika variabel produk $\left(\mathrm{X}_{1}\right)$, harga $\left(\mathrm{X}_{2}\right)$, kualitas pelayanan $\left(\mathrm{X}_{3}\right)$, promosi $\left(\mathrm{X}_{4}\right)$ dan lokasi $\left(\mathrm{X}_{5}\right)$ dianggap konstan, atau sama dengan nol, maka keputusan konsumen berkunjung (Y) akan tetap sebesar 6,626.

2. Koefisien regresi $\left(\beta_{1}\right)$ sebesar $-0,151$, artinya apabila setiap penurunan satu satuan variabel produk $\left(\mathrm{X}_{1}\right)$ dengan asumsi variabel harga $\left(\mathrm{X}_{2}\right)$, kualitas pelayanan $\left(\mathrm{X}_{3}\right)$, promosi $\left(\mathrm{X}_{4}\right)$ dan lokasi $\left(\mathrm{X}_{5}\right)$ dianggap konstan, maka akan menaikan keputusan konsumen berkunjung (Y) sebesar -0,151 satuan, sebaliknya apabila produk mengalami penaikan sebesar satu poin maka produk akan mengalami penurunan.

3. Koefisien regresi $\left(\beta_{2}\right)$ sebesar 0,367 , artinya setiap penambahan satu satuan variabel harga $\left(\mathrm{X}_{2}\right)$ dengan asumsi variabel produk $\left(\mathrm{X}_{1}\right)$, kualitas pelayanan $\left(\mathrm{X}_{3}\right)$, promosi $\left(\mathrm{X}_{4}\right)$ dan lokasi $\left(\mathrm{X}_{5}\right)$ dianggap konstan, maka akan 
meningkatkan keputusan konsumen berkunjung (Y) sebesar 0,367 satuan.

4. Koefisien regresi $\left(\beta_{3}\right)$ sebesar 0,510 , artinya setiap penambahan satu satuan variabel kualitas pelayanan $\left(\mathrm{X}_{3}\right)$, dengan asumsi variabel produk $\left(\mathrm{X}_{1}\right)$, harga $\left(\mathrm{X}_{2}\right)$, promosi $\left(\mathrm{X}_{4}\right)$ dan lokasi $\left(\mathrm{X}_{5}\right)$ dianggap konstan maka akan meningkatkan keputusan konsumen berkunjung $(\mathrm{Y})$ sebesar 0,510 satuan.

5. Koefisien regresi $\left(\beta_{4}\right)$ sebesar 0,328 , artinya setiap penambahan satu satuan variabel promosi $\left(\mathrm{X}_{4}\right)$, dengan asumsi variabel produk $\left(\mathrm{X}_{1}\right)$, harga $\left(\mathrm{X}_{2}\right)$, kualitas pelayanan $\left(\mathrm{X}_{3}\right)$ dan lokasi $\left(\mathrm{X}_{5}\right)$ maka akan menaikan keputusan konsumen berkunjung (Y) sebesar 0,328 satuan.

6. Koefisien regresi $\left(\beta_{5}\right)$ sebesar $-0,145$, artinya apabila setiap penurunan satu satuan variabel lokasi $\left(\mathrm{X}_{5}\right)$ dengan asumsi variabel produk $\left(\mathrm{X}_{1}\right)$, harga $\left(\mathrm{X}_{2}\right)$, kualitas pelayanan $\left(\mathrm{X}_{3}\right)$, dan promosi $\left(\mathrm{X}_{4}\right)$ dianggap konstan, maka akan menaikan keputusan konsumen berkunjung (Y) sebesar -0,145 satuan, sebaliknya apabila lokasi mengalami penaikan sebesar satu poin maka lokasi akan mengalami penurunan.

\section{Uji t (Uji Parsial)}

Uji t atau uji parsial digunakan untuk mengetahui pengaruh masing- masing variabel bebas terhadap variabel terikat. Apabila $t_{\text {hitung }}>t_{\text {tabel }}$ dan signifikan $<0,05$ maka variabel bebas memberikan pengaruh yang signifikan terhadap variabel terikatnya, sedangkan apabila $t_{\text {hitung }}<t_{\text {tabel }}$ dan signifikan > 0,05 maka variabel bebas tidak memberikan pengaruh yang signifikan terhadap variabel terikatnya (Ghozali, 2012).

\section{Tabel 6 Uji t}

\begin{tabular}{lccc}
\hline $\begin{array}{l}\text { Variabel } \\
\text { Penelitian }\end{array}$ & $\mathrm{t}_{\text {hitung }}$ & $\begin{array}{c}\mathrm{t}_{\text {tabel }} \\
(\mathrm{df}=0,025 ; \\
25)\end{array}$ & $\begin{array}{c}\text { Signifikansi } \\
(0,05)\end{array}$ \\
\hline $\begin{array}{l}\text { (Contant) } \\
\text { Produk } \\
\left(\mathrm{X}_{1}\right)\end{array}$ & 1,365 & 2,05954 & 0,185 \\
$\begin{array}{l}\text { Harga }\left(\mathrm{X}_{2}\right) \\
\text { Kualitas }\end{array}$ & 2,450 & 2,05954 & 0,440 \\
$\begin{array}{l}\text { Pelayanan } \\
\left(\mathrm{X}_{3}\right)\end{array}$ & 2,259 & 2,05954 & 0,022 \\
$\begin{array}{l}\text { Promosi } \\
\left(\mathrm{X}_{4}\right)\end{array}$ & 2,231 & 2,05954 & 0,033 \\
$\begin{array}{l}\text { Lokasi } \\
\left(\mathrm{X}_{5}\right)\end{array}$ & $-0,677$ & 2,05954 & 0,035 \\
\hline Sumber & & & \\
\hline
\end{tabular}

Sumber: Data Primer yang diolah, 2020

Berdasarkan tabel 6 uji t, dapat dijelaskan sebagai berikut:

1. Produk $\left(\mathrm{X}_{1}\right)$ menunjukan bahwa variabel produk tidak memiliki pengaruh positif dan signifikan terhadap keputusan konsumen berkunjung (Y). Secara parsial memiliki nilai $\mathrm{t}_{\text {hitung }}-0,785<\mathrm{t}_{\text {tabel }} 2,059$ dengan signifikansi $0,440>0,05$, sehingga hipotesis pertama H0 diterima, sedangkan H1 ditolak. Hal ini tidak sesuai dengan penelitian Kurniasari dan Santoso (2013), menyatakan bahwa kualitas produk 
mempunyai pengaruh langsung terhadap keputusan pembelian. Pernyataan tersebut menunjukan jika produk yang diberikan kepada konsumen memiliki kualitas yang baik dan sesuai dengan keinginan konsumen akan mendorong konsumen untuk melakukan pembelian. Konsumen melakukan pembelian suatu produk bertujuan untuk memenuhi kebutuhan dan manfaat tertentu. Karakteristik produk tidak hanya meliputi aspek non fisik (intangible features) seperti citra rasa, namun dapat juga dilihat dari aspek fisik produk tersebut (tengible features) (Sulistianingrum, 2014).

2. Harga $\left(\mathrm{X}_{2}\right)$ menunjukan bahwa variabel harga memiliki pengaruh positif dan signifikan terhadap keputusan konsumen berkunjung (Y). Secara parsial memiliki nilai $\mathrm{t}_{\text {hitung }}$ $2,450>t_{\text {tabel }}$ 2,059 dengan signifikansi $0,022<0,05$, sehingga hipotesis pertama H0 ditolak, sedangkan H1 diterima. Hal ini sesuai dengan penelitian Warisan dan Harianto (2018), menyatakan bahwa harga berpengaruh positif dan signifikan terhadap keputusan konsumen dalam melakukan pembelian. Strategi penentapan harga merupakan salah satu hal yang harus diperhatikan suatu perusahaan. Kampoeng Banyumili telah melakukan strategi penetapan harga yang tepat, dengan adanya penetapan harga yang terjangkau dan kesesuaian harga dengan keinginan konsumen, maka konsumen cenderung tertarik untuk melakukan pembelian. Harga yang terjangkau adalah salah satu daya tarik konsumen dalam menentukan keputusan pembeliannya. Sehingga konsumen akan membandingkan persepsi antara manfaat dengan biaya-biaya yang dikeluarkan untuk mendapatkan suatu produk. Dengan kata lain harga dapat didefinisikan sebagai kemampuan seseorang dalam menilai suatu barang dengan satuan alat ukur rupiah untuk dapat memperoleh produk yang diinginkan (Iralisa, 2017). Pernyataan tersebut diperkuat dengan hasil penelitian Isa dkk (2018), menyatakan bahwa harga berpengaruh positif dan signifikan terhadap keputusan konsumen melakukan pembelian. Hal ini menunjukan bahwa semakin baik pemilihan harga yang ditawarkan perusahaan akan meningkatkan keputusan konsumen terhadap produk tersebut.

3. Kualitas pelayanan $\left(\mathrm{X}_{3}\right)$ menunjukan bahwa variabel kualitas pelayanan 
memiliki pengaruh positif dan signifikan terhadap keputusan konsumen berkunjung (Y). Secara parsial memiliki nilai $t_{\text {hitung }} 2,259>t_{\text {tabel }}$ 2,059 dengan signifikansi 0,033 $<0,05$, sehingga hipotesis pertama $\mathrm{H} 0$ ditolak, sedangkan H1 diterima. Hal ini sesuai dengan penelitian Kurniasari dan Santoso (2013), menyatakan bahwa kualitas pelayanan berpengaruh positif dan signifikan terhadap keputusan konsumen melakukan pembelian. Kualitas pelayanan merupakan ukuran seberapa baik tingkat pelayanan yang diberikan perusahaan kepada konsumen. Pelayanan yang baik akan menciptakan rasa kepuasan tersendiri bagi konsumen. Kualitas pelayanan memiliki pengaruh yang tinggi untuk mendatangkan konsumen. Semakin baik kualitas pelayanan yang diberikan oleh perusahaan tersebut, maka akan menimbulkan dampak yang positif bagi perusahaan tersebut (Lupiyoadi, 2009). Kampoeng Banyumili telah memberikan pelayanan yang baik kepada setiap konsumen yang datang berkunjung. Hal ini dapat dilihat dari cara karyawan Kampoeng Banyumili menjaga kesopanan, kebersihan, kerapian dalam berpenampilan, daya tanggap, kecepatan dan kemampuannya dalam menanggapi permintaan konsumen, serta mampu memberikan informasi dan rasa aman kepada setiap konsumen yang datang.

4. Promosi $\left(\mathrm{X}_{4}\right)$ menunjukan bahwa variabel promosi memiliki pengaruh positif dan signifikan terhadap keputusan konsumen berkunjung (Y). Secara parsial memiliki nilai $t_{\text {hitung }}$ $2,231>t_{\text {tabel }} 2,059$ dengan signifikansi $0,035<0,05$, sehingga hipotesis pertama H0 ditolak, sedangkan $\mathrm{H} 1$ diterima. Hal ini sesuai dengan penelitian Tantia (2017), menyatakan bahwa promosi berpengaruh positif dan signifikan terhadap keputusan konsumen. Promosi merupakan faktor penting dalam suatu perusahaan karena melalui promosi konsumen akan mengetahui keunggulan produk yang ditawarkan. Promosi dapat dikatakan sebagai alat komunikasi yang dilakukan perusahaan untuk memberikan informasi, membujuk atau menghimbau konsumen dalam proses keputusan pembelian. Hasil penelitian ini sesuai dengan penelitian Mardiyanidan dan Murwatiningsih (2015), menyatakan bahwa terdapat pengaruh langsung promosi terhadap keputusan konsumen. Artinya semakin tinggi promosi yang dilakukan suatu 
perusahaan makan akan meningkatkan keputusan konsumen. Kampoeng Banyumili melakukan promosi melalui media sosial instagram dan melalui web resmi Kampoeng Banyumili. Selain melalui media elektronik, promosi juga dilakukan melalui mulut ke mulut. Promosi yang dilakukan Kampoeng Banyumili dapat dikatakan sudah baik, karena sebagian pengunjung mampu mendapatkan informasi dari media promosi tersebut.

5. Lokasi $\left(\mathrm{X}_{5}\right)$ menunjukan bahwa variabel lokasi tidak memiliki pengaruh positif dan signifikan terhadap keputusan konsumen berkunjung (Y). Secara parsial memiliki nilai $\mathrm{t}_{\text {hitung }}-0,677<\mathrm{t}_{\text {tabel }} 2,059$ dengan signifikansi $0,505>0,05$, sehingga hipotesis pertama $\mathrm{H} 0$ diterima, sedangkan H1 ditolak. Penelitian ini tidak sesuai dengan penelitan Kriswanto, (2011), menyatakan bahwa lokasi berpengaruh positif dan signifikan terhadap keputusan konsumen berkunjung. Hal ini terjadi karena sebagian besar konsumen yang datang berkunjung ke Kampoeng Banyumili tidak menjadikan lokasi sebagai suatu kendala. Kemudahan akses jalan, lingkungan, tempat parkir dan suasana yang diciptakan Kampoeng Banyumili menjadikan daya tarik tersendiri bagi konsumen. Konsumen yang data berkunjung pada Kampoeng Banyumili adalah orang yang berasal dari luar kota, sehingga konsumen rela mengunjungi Kampoeng Banyumili walaupun jarak yang ditempuh cukup jauh. Pemilihan lokasi yang strategis merupakan hal yang penting bagi suatu perusahaan karena lokasi bertujuan untuk menentukan kesusksesan perusahaan tersebut.

\section{Uji F (Uji Simultan)}

Uji $F$ atau uji simultan digunakan untuk mengetahui sejauh mana variabelvariabel bebas memiliki pengaruh secara bersama-sama atau parsial terhadap variabel terikat (Ghozali, 2012).

\section{Tabel 7 Uji F}

\begin{tabular}{lrrcr}
\hline \multicolumn{1}{c}{ Model } & $\begin{array}{c}\text { Mean } \\
\text { Square }\end{array}$ & Fhitung & $\begin{array}{c}\text { Ftabel } \\
\mathrm{df}= \\
5 ; 25\end{array}$ & Sig. \\
\hline $\begin{array}{l}\text { Regression } \\
\text { Residual }\end{array}$ & $\begin{array}{r}18.283 \\
2.498\end{array}$ & 7.319 & 2,60 & $.000^{\mathrm{a}}$ \\
\hline
\end{tabular}

Sumber: Data Primer yang diolah, 2020

Berdasarkan tabel 7 uji f, menunjukan nilai $F_{\text {hitung }}$ sebesar 7,319 dan $\mathrm{F}_{\text {tabel }}$ 2,62 dengan nilai signifkan sebesar 0,000 . Karena nilai $F_{\text {hitung }} 7,319>F_{\text {tabel }}$ 2,62 dan signifikan $0,000<0,05$, maka dapat disimpulkan bahwa variabel bebas secara bersama-sama memiliki pengaruh yang signifikan terhadap variabel terikat. Hal ini sesuai dengan teori yang 
dikemukanan Ghozali (2012), menyatakan bahwa variabel bebas secara bersama-sama memiliki pengaruh yang signifikan jika $F_{\text {hitung }}>F_{\text {tabel }}$ dan signifikan $<0,05$.

\section{Uji Koefisien Determinasi $\left(\mathbf{R}^{2}\right)$}

Uji Koefisien determinasi $\left(\mathrm{R}^{2}\right)$ digunakan untuk mengetahui seberapa jauh kemampuan model dalam menerangkan variasi variabel terikat (Ghozali, 2012).

Tabel 8 Koefisien Determinasi

\begin{tabular}{lrrrr}
\hline Model & $\mathrm{R}$ & $\begin{array}{c}\mathrm{R} \\
\text { Square }\end{array}$ & $\begin{array}{r}\text { Adjusted } \\
\text { R Square }\end{array}$ & $\begin{array}{l}\text { Std. Error of } \\
\text { the Estimate }\end{array}$ \\
\hline 1 & $.777^{\mathrm{a}}$ & .604 & .521 & 1.581 \\
\hline
\end{tabular}

Sumber: Data Primer yang diolah, 2020

Berdasarkan tabel 8, menyatakan bahwa nilai $\mathrm{R}$ square $\left(\mathrm{R}^{2}\right)$ sebesar 0,604. Hal ini menunjukan bahwa keputusan konsumen (Y) dapat dijelaskan oleh variabel Produk $\left(\mathrm{X}_{1}\right)$, variabel harga $\left(\mathrm{X}_{2}\right)$, variabel kualitas pelayanan $\left(\mathrm{X}_{3}\right)$, variabel Promosi $\left(\mathrm{X}_{4}\right)$ dan variabel lokasi $\left(\mathrm{X}_{5}\right)$ sebesar $60,4 \%$. Sedangkan sisanya sebesar $39,6 \%$ dipengaruhi oleh variabel diluar variabel yang diteliti.

\section{KESIMPULAN DAN SARAN}

Berdasarkan hasil penelitian dan pembahasan diatas dapat disimpulkan bahwa variabel harga $\left(\mathrm{X}_{2}\right)$, kualitas pelayanan $\left(\mathrm{X}_{3}\right)$ dan promosi $\left(\mathrm{X}_{4}\right)$ memiliki pengaruh positif dan signifikan terhadap keputusan konsumen berkunjung (Y), sedangkan produk $\left(\mathrm{X}_{1}\right)$ dan lokasi $\left(\mathrm{X}_{5}\right)$ tidak memiliki pengaruh yang signifikan terhadap keputusan konsumen berkunjung (Y) di Kampoeng Banyumili. Saran untuk penelitian selanjutnya dapat menggunakan variabel faktor budaya dan sosial.

\section{DAFTAR PUSTAKA}

Arikunto, S., 2006. Prosedur Penelitian Suatu Pendekatan Praktik. Jakarta: Rineka Cipta.

Ghozali, I., 2012. Aplikasi Analisis Multivariate dengan Program IBM SPSS. Semarang: UNDIP.

Iralisa, Y., 2017. Pengaruh Marketing Mix (Produk, Harga, Lokasi dan Promosi) Terhadap Loyalitas Pelanggan Dunkin Donuts Bandar Lampung. Skripsi Fakultas Keguruan dan Ilmu Pendidikan Universitas Lampung.

Isa, Muzakar, Ahmad Mardalis, dan L. M., 2018. Analisis Keputusan Konsumen Dalam Melakukan Pembelian Makanan dan Minuman di Warung Hik. Jurnal Ekonomi Manajemen Sumber Daya, 20, 1.

Kotler, P. dan Amstrong, 2001. Prinsip Prinsip Pemasaran Jilid I. Jakarta: Erlangga.

Kriswanto, A. H., 2011. Pengaruh Harga, Lokasi dan Fasilitas Terhadap Keputusan Berkunjung Wisatawan di Obejek Wisata Dampo Awang Beach Rembang. Skripsi Jurusan Manajemen Fakultas Ekonomi Universitas Negeri Semarang.

Kurniasari, N. D. \& Santoso, S. B., 2013. Analisis Pengaruh Harga, Kualitas Produk, dan Kualitas Pelayanan Terhadap Keputusan Pembelian (Studi Kasus pada Konsumen Waroeng Steak \& Shake Cabang Jl. Sriwijaya 11 Semarang). Diponegoro Journal Of Management, 2, 2337-3792. 
Lupiyoadi, R., 2009. Manajemen Pemasaran Jasa. Edisi Ke-2. Jakarta: Salemba Empat.

Mardiyani, Y. \& M., 2015. Pengaruh Harga, Lokasi dan Fasilitas Terhadap Keputusan Berkunjung Wisatawan di Obejek Wisata Dampo Awang Beach Rembang. Management Analysis Journal, 4 (1), 65-75.

Priyatno, D., 2013. Mandiri Belajar Analisis Data Dengan SPSS. Yogyakarta: Mediacom.

Puspita, D. A., 2014. Faktor-Faktor yang Mempengaruhi Keputusan Pembelian di Restoran Waroeng Taman Kota Bogor. Skripsi Institut Pertanian Bogor.

Setiadi, N., 2010. Prilaku Konsumen: Perseptif Konterporer pada Motif, Tujuan dan Keinginan Konsumen. Jakarta: Kencana Perenada Media Group.

Sugiyono, 2009. Metode Penelitian Kuantitatif, Kualitatif dan $R \& D$.
Bandung: Alfabeta, CV.

Sulistianingrum, U., 2014. Pengaruh

Kualitas Produk dan Layanan Terhadap Keputusan Konsumen di Restoran Koki Tappanyaki Express. Yogyakarta. Skripsi Fakultas Teknik Universitas Negeri Yogyakarta.

Tantia, D. R., 2017. Pengaruh Kualitas Pelayanan, Harga, Promosi dan Kualitas Produk Tehadap Keputusan Pembelian Pada Makanan Cepat Saji KFC Coffe Kedaton Bandar Lampung. Skripsi Fakultas Keguruan dan Ilmu Pendidikan Universitas Lampung.

Umar, H., 2005. Metode Penelitian Untuk Skripsi dan Tesis Bisnis. Jakarta: PT. Raja Grafindo Persada.

Warisan, J. \& Harianto, A., 2018. Faktor Yang Mempengaruhi Keputusan Konsumen Dalam Memilih Restoran "All You Can Eat" Di Surabaya. [Online]. 